\title{
Quantifying loss aversion: Evidence from a UK population survey
}

\author{
David Blake $^{1}$ (D) Edmund Cannon ${ }^{2}$ (D) $\cdot$ Douglas Wright $^{1}$ (D)
}

Accepted: 23 July 2021 / Published online: 8 October 2021

(c) The Author(s) 2021

\begin{abstract}
We quantify differences in attitudes to loss from individuals with different demographic, personal and socio-economic characteristics. Our data are based on responses from an online survey of a representative sample of over 4000 UK residents and allow us to produce the most comprehensive analysis of the heterogeneity of loss aversion measures to date. Using the canonical model proposed by Tversky and Kahneman (1992), we show that responses for the population as a whole differ substantially from those typically provided by students (who form the basis of many existing studies of loss aversion). The average aversion to a loss of $£ 500$ relative to a gain of the same amount is 2.41 , but loss aversion correlates significantly with characteristics such as gender, age, education, financial knowledge, social class, employment status, management responsibility, income, savings and home ownership. Other related factors include marital status, number of children, ease of savings, rainy day fund, personality type, emotional state, newspaper and political party. However, once we condition on all the profiling characteristics of the respondents, some factors, in particular gender, cease to be significant,
\end{abstract}

\footnotetext{
Statement by YouGov: YouGov maintains a highly engaged panel of over 5 million respondents worldwide, who have specifically opted in to participate in online research activities (both qualitative and quantitative). The value of our panel, as opposed to many other types of online sample sources, lies in having continuous access to a responsive audience ready-profiled on important demographic, attitudinal and lifestyle attributes. Engagement with panellists is maintained via a transparent points based reward system for the completion of surveys. Sophisticated sampling techniques ensure that members are always given a survey to complete, meaning that being screened out of a survey doesn't equal no reward, reducing the propensity to claim or misremember behaviour for fear of missing out on reward. Panellists also have their own portal and web community through which they can communicate with each other and which is used to make them aware of the impact of their contribution, via regular newsletters highlighting media coverage of YouGov and sharing findings from key surveys (that aren't commercially sensitive). On average, panellists complete a survey no more than once per week, a threshold that ensures continued engagement without over-burdening panellists with too many surveys. We monitor and control the number and frequency of invitations and completions both at an overall level and within subject areas. Respondents are not informed of the specific survey topic to minimise response bias based on the panellists' own level of interest in the subject matter.
}

Extended author information available on the last page of the article 
suggesting that gender differences in risk and loss attitudes might be due to other factors, such as income differences.

Keywords Loss aversion - Gender effects · Expected utility · Risk attitudes · Survey data

JEL Classification G40 · D40 · C83 · C90

\section{Introduction}

The simplest canonical models in economics assume that agents have identical preferences and that they maximise the expected value of a concave utility function. In this paper, we use survey data to contribute to the literature both on heterogeneous agents and on more sophisticated models of human behaviour. Our data are collected from a survey of 4016 respondents who form a representative sample of individuals in the United Kingdom and we are able to correlate loss aversion and risk attitude with a rich set of demographic and socio-economic variables, as well as self-reported character traits such as optimism and competitiveness. Using the standard parametric model of loss aversion first proposed by Kahneman and Tversky (1979), we show that responses are consistent with loss aversion, but that attitudes to risk in both the gain and loss domains are significantly correlated with reported characteristics of the respondents. We contrast our results with those of comparable studies which are frequently based on the analysis of university students and show that such students are unrepresentative of the population as a whole.

For at least fifty years, economists have been aware that the expected utility (EU) model might not fully capture consumer behaviour under risk (Allais 1953; Rabin and Thaler, 2001; Samuelson 1963) and this has led to a range of more general models being proposed. Simply put, the EU model assumes that the objective function depends on two components: first, the value (or utility, loosely defined) of a state depends upon the consumption or wealth in that state without regard to how it was reached; second, when considering more than one possible outcome, the different states of the world are weighted by the subjective probability of each state occurring. In the specific example of the EU model, the objective function is:

$$
\sum_{i} p_{i} u\left(c_{i}\right)
$$

where $u\left(c_{i}\right)$ is a standard increasing and concave utility function depending upon consumption (or wealth) in each state $i$ and $p_{i}$ is the associated probability of that state occurring.

Kahneman and Tversky (1979) suggested changing both of these components so that the objective function becomes:

$$
\sum_{i} w\left(p_{i}\right) v\left(x_{i}\right)
$$


replacing the standard utility function with a more general value function and weighting the outcomes not by the probabilities but by a function of the probabilities.

In this paper, we confine our analysis to the standard model proposed by Tversky and Kahneman (1992) and hence use a widely accepted framework to compare the loss and risk attitudes of different respondents. In particular, we use the CRRA (constant relative risk aversion or iso-elastic) form of the value function which depends upon gains and losses, $x$, relative to the initial position:

$$
v(x)= \begin{cases}v^{+}(x)=x^{\alpha} & \text { if } x \geq 0 \\ -\lambda v^{-}(x)=-\lambda(-x)^{\beta} & \text { if } x<0\end{cases}
$$

where $\lambda$ measures "direct" loss aversion, defined as the ratio of the value of a loss of one unit of currency to the value of a gain of one unit of currency. The parameter $\alpha$ measures risk attitude in the domain of gains. There is risk aversion in the domain of gains if $\alpha<1$ and this is higher for lower values of $\alpha$; there is risk seeking in the domain of gains if $\alpha>1$. The parameter $\beta$ measures risk attitude in the domain of losses. There is risk seeking in the domain of losses if $\beta<1$ and this is higher if $\beta$ is lower; there is risk aversion in the domain of losses if $\beta>1$. There is risk neutrality in the relevant domain when these parameters take a value of unity.

In this paper, we estimate the value function, but we do not attempt to model the more sophisticated treatment of probabilities embodied in Eq. (2), i.e., to estimate the weighting function $w\left(p_{i}\right)$. There are two reasons for this.

First, existing studies show that the effect of the weighting function is most important when probabilities are close to either zero or unity. Abdellaoui et al. (2008) find $w(0.5)=0.46$ in the gain domain and $w(0.5)=0.45$ in the loss domain, suggesting we can assume $w\left(p_{i}\right)=p_{i}$ without a serious reduction in accuracy. Bleichrodt et al. (2001) suggest that using probabilities of one-third might reduce bias in parameter estimates, but we chose to use a probability of one half in our survey questions, because the 50:50 scenario is likely to involve the smallest cognitive load for the respondents.

Second, there are significant trade-offs that need to be made when calibrating a utility or value function using real-world data. Studies of behaviour in response to loss and risk are usually based on questionnaires of a relatively small number of homogeneous individuals who are typically students of the authors of those studies. For example, Harrison and Swarthout (2016, Table 2) list papers testing or estimating models of loss aversion and the last ten of these references analyse a total of twelve data sets, nine of which are based on students with a sample size ranging from 30 to 177 respondents. The three exceptions are Scholten and Read's (2014) Yale University data set of 569 online respondents (many of whom may also have been students), Abdellaoui et al.'s (2013) analysis of 65 couples and von Gaudecker et al.'s (2011) survey of a representative sample of 1422 individuals from the Netherlands. Our analysis is closest to that of von Gaudecker et al. (2011) who also choose to ignore the probability weighting issue. There is, however, an important difference in the value functions in the loss domain between their study and ours. In 
the loss domain, we find that the value function is convex as a function of $x$, whereas von Gaudecker et al. (2011), using the utility function of Kreps and Porteus (1978), assume that disutility is concave.

The advantage of a data set involving students is that the respondents are usually willing (indeed required) to answer a sufficiently large number of questions - often about a hundred-to identify relatively complicated functional forms of both the value function and the weighting function; furthermore, the financial cost of recruiting students is relatively low. The corresponding disadvantage is that the study only reveals information on student-aged individuals selected for university education and whose understanding of risk may be conditioned by what they have already been taught (since they are often Economics, Finance or MBA students). Since estimated utility and value functions might be used to analyse the savings behaviour of poorlyeducated individuals or the decumulation behaviour of pensioners, using estimates of risk or loss aversion from such studies may be inappropriate.

Our data set is for a representative sample of the UK adult population and contains a large number of variables describing the economic, social, political and personal characteristics of the respondents. The trade-off from having access to such a rich data set is that we were unable to ask a large number of questions because the agency conducting the survey was concerned that if the experiment was too onerous it might put off respondents from completing it. The average time spent by respondents on the questions we asked was 29 min, shorter than the time reported in many experimental studies, which is typically between $40 \mathrm{~min}$ and $1 \mathrm{~h}$. We were able to ask sufficient questions to identify the value function but not the weighting function.

To give a flavour of the issues that we consider, we summarise some of our findings in Figs. 1 and 2. Figure 1 illustrates our estimate of the value function for our whole sample, ignoring the heterogeneity of respondents: this figure is based entirely on our estimates of $\alpha, \beta$ and $\lambda$ in Eq. (3). These estimated values provide evidence for three stylised facts: first, the $S$-shaped value function posited by Kahneman and Tversky (1979) where the value function is concave in the gain domain and convex in the loss domain (whereas with EU the value function would be concave in the loss domain); second, the older insight (which can be traced back to Samuelson 1963) that the disutility of losses is greater than the utility of gains, commonly known as "loss aversion"; and third, that the value function is less convex in the loss domain than it is concave in the gain domain, i.e., $\beta>\alpha$, implying that the marginal disutility of losses exceeds the marginal utility of gains.

We show that these three qualitative findings hold not only for the whole sample but for any sub-sample of the data: for example, they hold for both men and women, at any age, for any level of income, for any level of education, although quantitatively the value functions vary considerably for each subgroup.

We now turn to the issue of quantifying loss aversion more precisely, since there is more than one possible definition. ${ }^{1}$ A popular measure of "relative loss aversion" proposed by Köbberling and Wakker (2005) is:

\footnotetext{
${ }^{1}$ We discuss this in more detail in Online Appendix 4, following the approach of Abdellaoui et al. (2007).
} 


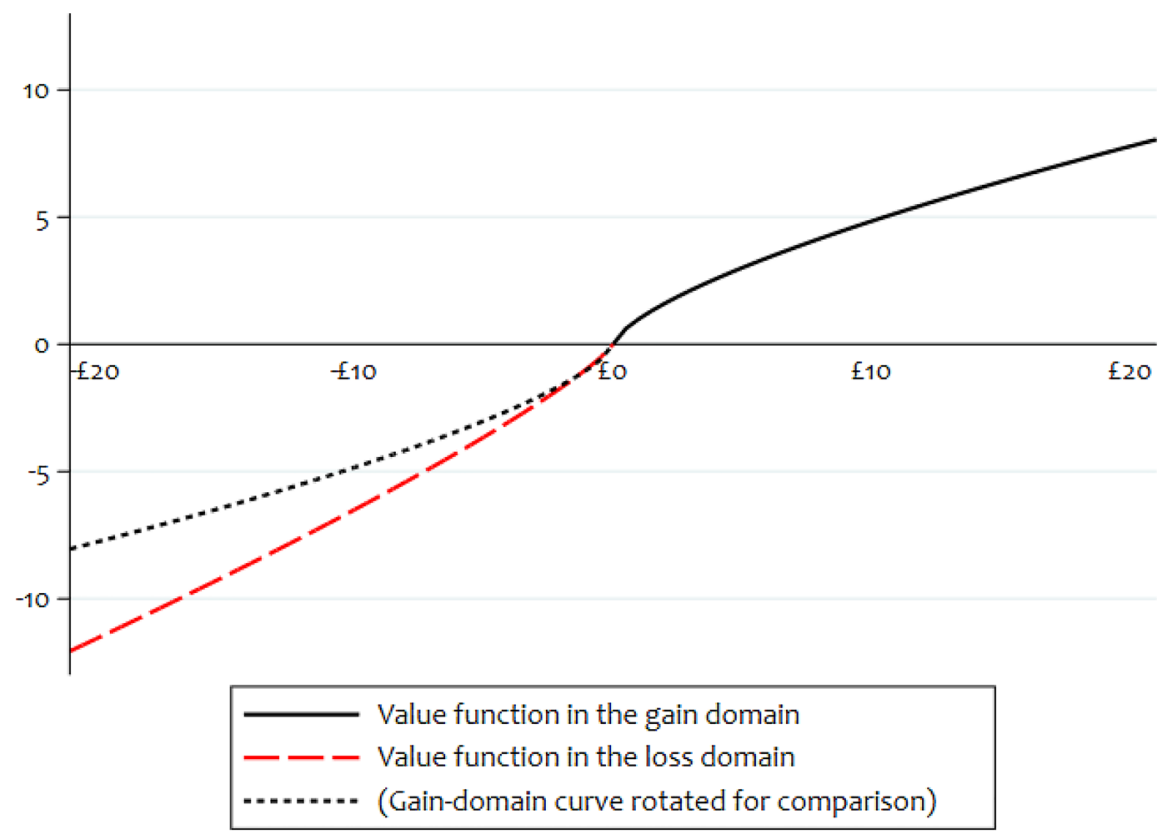

Fig. 1 The estimated value function for the full sample of respondents

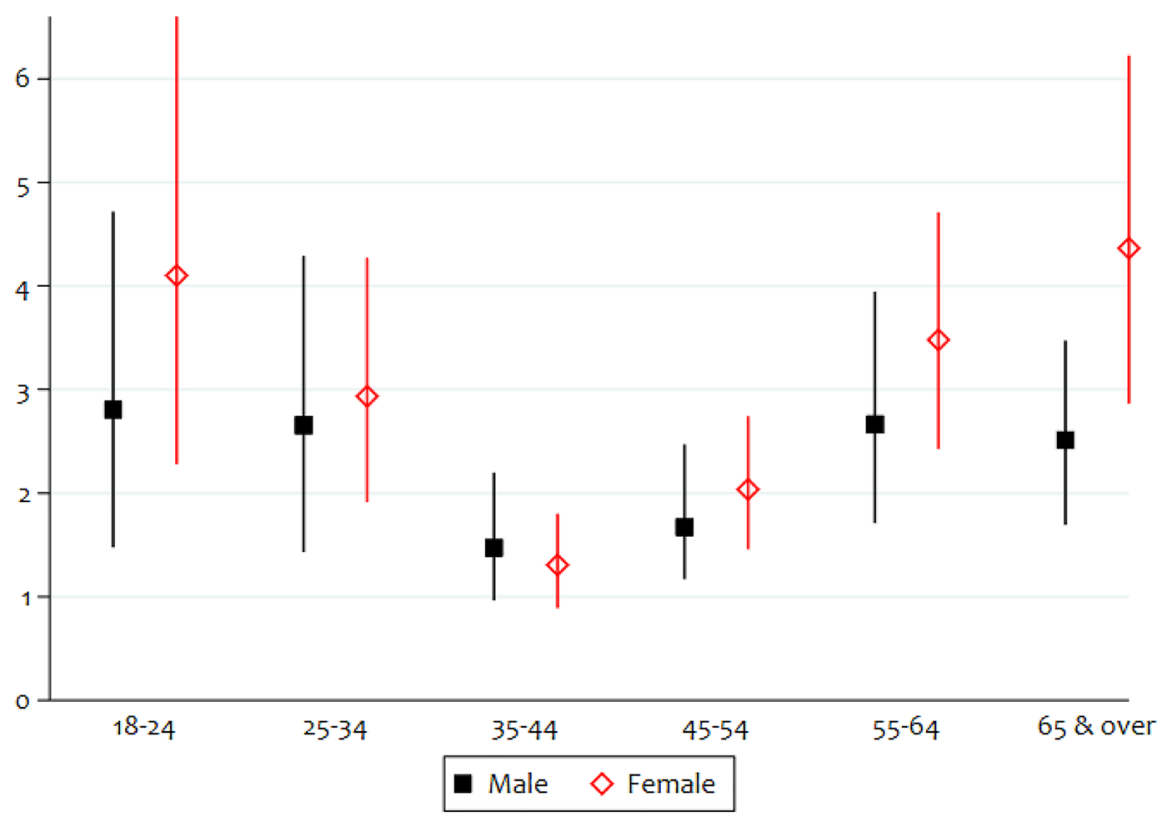

Fig. 2 Relative loss aversion with a gain or loss of 500, $\Lambda(500)$, across gender and age. Note The figure shows the expected value of $\Lambda(500)$ and the associated $90 \%$ confidence interval. The numbers in this figure come from Table A4 in Online Appendix 2. The graph would have a similar shape if we plotted $\Lambda(x)$ for other values of $x$ 


$$
\frac{v_{\uparrow}^{\prime}(0)}{v_{\downarrow}^{\prime}(0)}=-\lambda \frac{\lim _{x>0} v^{-\prime}(x)}{\lim _{x \searrow 0} v^{+\prime}(x)}
$$

which measures whether there is a "kink" in the value function at the origin. The hypothetical sums of money considered in our survey (with a minimum monetary value of 10 units of currency) are too large to allow us to analyse with any confidence what is happening for very small values of $x$ close to zero and so it would be inappropriate for us to use this definition. For larger values of $x$, possibly the most helpful definition is that of Zank (2010), who notes that the weighting function in the loss domain $w^{-}(p)$ may differ from the weighting function in the gain domain $w^{+}(p)$, suggesting the definition of loss aversion:

$$
-\lambda \frac{w^{-}(p) v^{-}(x)}{w^{+}(p) v^{+}(x)}
$$

However, as we have already explained, the restrictions placed on our data collection mean that we shall be unable to identify the weighting function(s) and so we use instead the more standard definition originating from Tversky and Kahneman (1992):

$$
\Lambda(x)=-\lambda \frac{v^{-}(x)}{v^{+}(x)}=-\lambda \frac{(-x)^{\beta}}{x^{\alpha}}
$$

which depends not only on the size of direct loss aversion, $\lambda$, but, in general, also on the sizes of $\alpha, \beta$ and $x$. Only in the cases of $\alpha=\beta$ or $x=1$ will $\Lambda(x)$ equal $\lambda$.

Figure 2 shows our point estimates and $90 \%$ confidence intervals for $\Lambda(500)$, estimated separately for our data broken down by gender and into six age groups. There is a strong U-shaped relationship between loss aversion and age; there is also evidence that women have slightly higher (unconditional) loss aversion than men at most ages. It is notable that loss aversion is highest among individuals in the age range 18-24, precisely the age group most likely to be analysed by studies based on university students.

While the associations are very strong, we do not claim that they imply a causal relationship since we have not controlled for other factors. To address the association of loss aversion with reported characteristics, we now turn to a detailed description of our study. In Sect. 2, we describe the survey design, elicitation method and sample of respondents. Our results are described in Sect. 3 and Sect. 4 concludes. We also have five online appendices.

\section{Survey design}

\subsection{Survey participants}

Our experimental data are taken from a survey conducted online by market research agency YouGov from 9 to 17th January 2017. There were 4018 respondents, of 
whom 4016 successfully completed the questions: the respondents were UK residents over the age of 18 . Individuals provided information on 25 variables which we shall discuss in detail later. ${ }^{2}$ We compare the characteristics of our sample to the population as a whole for some significant demographic and economic variables in Table 1. Relative to the national population, the sample is marginally (i) underweight young individuals (aged 18-34) and overweight middle-aged individuals (aged 45-64), (ii) underweight those on incomes below $£ 30,000$ and overweight those on incomes above $£ 30,000$, (iii) overweight social class A and underweight in social classes $\mathrm{C} 2$ and D, and (iv) underweight renters and overweight owner-occupiers (obviously these four factors may be related). Surveys of the national population covering income and savings also have a lower percentage of "no answer" than our survey. With these caveats, the sample was considered by YouGov to be broadly representative of the UK population and certainly more so than studies based on students: we discuss the issue of student responses in Sect. 3.2.

\subsection{Estimation method}

Our chosen method to elicit preferences was driven partly by the fact that respondents were being asked many other questions. To collect our data, we used the methodology advocated by Abdellaoui et al. (2008) which is based on the elicitation of the certainty equivalent of a number of different risky prospects. This method is also used by Abdellaoui et al. (2016), although that paper has a non-parametric model of preferences. Respondents are asked to choose between one risky and one certain outcome (a "choice task") rather than asking them to match the risky prospect with their own suggested certain outcome (a "match task") — as suggested by Frederick et al. (2002). ${ }^{3}$ In common with many studies, the gains and losses are hypothetical rather than actual: there are ethical problems in imposing actual losses on respondents apart from the financial problems involved when sums of money are significant. ${ }^{4}$

A potential alternative method based on a choice task would be some variant of the "multiple price list" method used by von Gaudecker et al. (2011) and described in detail by Andersen et al. (2006). Unfortunately, there is no clear reason to prefer one method over the other and we chose our method because of its convenience where time is limited and there is a corresponding need to minimise the cognitive burden on respondents.

\footnotetext{
2 These are gender, age, marital status, number of children, health status, two personality types, emotional state at the time of completing the survey, education, financial knowledge, social class, employment status, management responsibility, employment sector, job security, income, home ownership, savings, ease of short-term saving, rainy day fund, region, newspaper, political party, religion, and religiosity.

3 Respondents can find match tasks confusing and give implausible answers (Bostic et al. 1990). In an earlier study, we used a match task approach, but the results contained too many inconsistent answers to be plausible and the study was abandoned.

4 Most previous studies have shown that the results are similar whether hypothetical or real rewards (e.g., Beattie and Loomes 1997; Camerer and Hogarth 1999) and losses (e.g., Etchart-Vincent and L'Haridon 2011) are used. However, Holt and Laury (2002) found that the use of real incentives increased risk aversion.
} 


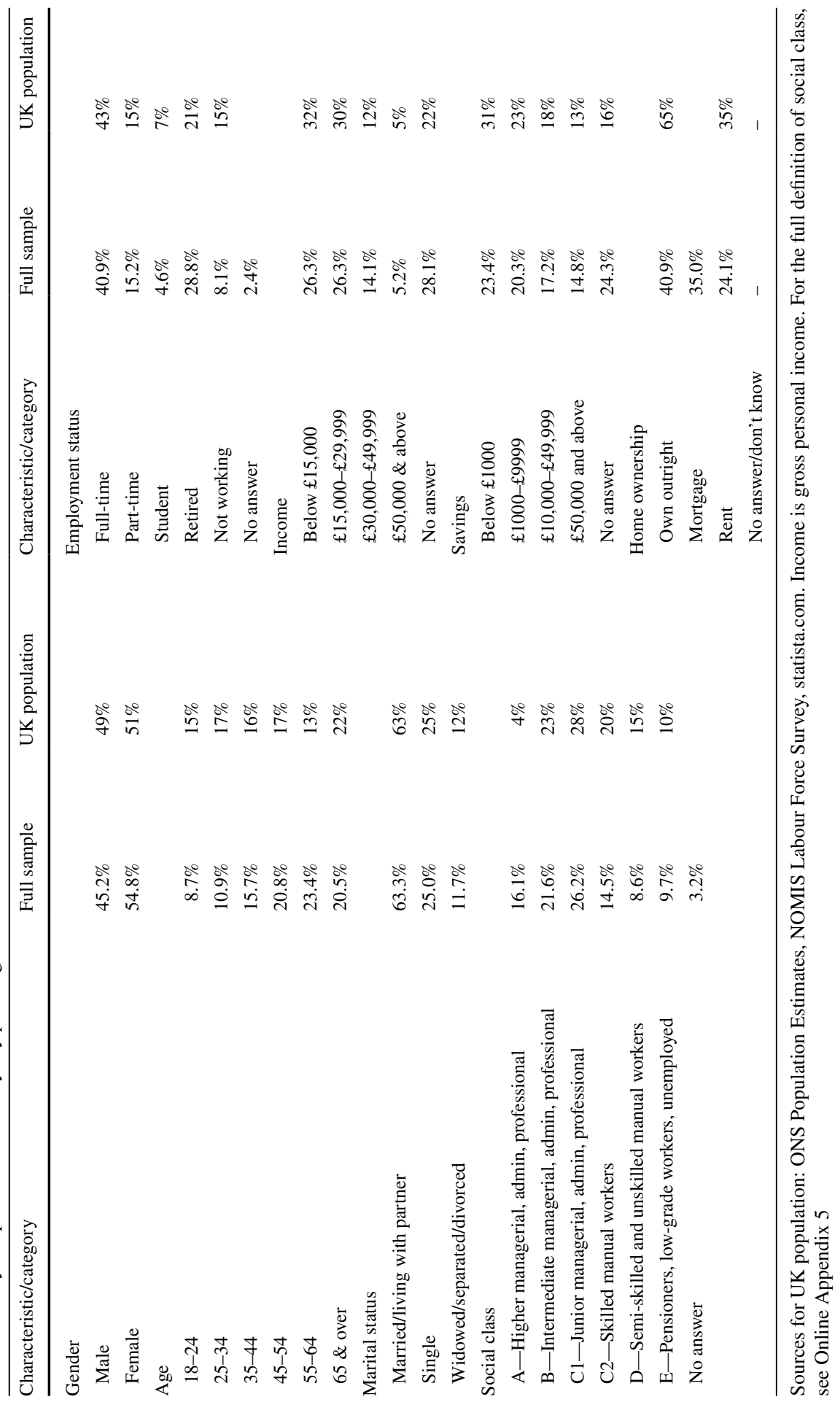


Table 2 The prospects presented to each individual

\begin{tabular}{|c|c|c|}
\hline & Risky prospect & Certain prospect \\
\hline \multicolumn{3}{|l|}{ Gains only } \\
\hline Prospect 1 & $\begin{array}{l}50 \% \text { chance of a gain of } £ 0 \text { and } 50 \% \text { chance of a gain } \\
\text { of } £ 10\end{array}$ & Certainty equivalent, $G_{1}$ \\
\hline Prospect 2 & $\begin{array}{l}50 \% \text { chance of a gain of } £ 0 \text { and } 50 \% \text { chance of a gain } \\
\text { of } £ 100\end{array}$ & Certainty equivalent, $G_{2}$ \\
\hline Prospect 3 & $\begin{array}{l}50 \% \text { chance of a gain of } £ 0 \text { and } 50 \% \text { chance of a gain } \\
\text { of } £ 1000\end{array}$ & Certainty equivalent, $G_{3}$ \\
\hline \multicolumn{3}{|l|}{ Losses only } \\
\hline Prospect 4 & $\begin{array}{l}50 \% \text { chance of a loss of } £ 0 \text { and } 50 \% \text { chance of a loss } \\
\text { of } £ 10\end{array}$ & Certainty equivalent, $L_{4}$ \\
\hline Prospect 5 & $\begin{array}{l}50 \% \text { chance of a loss of } £ 0 \text { and } 50 \% \text { chance of a loss } \\
\text { of } £ 100\end{array}$ & Certainty equivalent, $L_{5}$ \\
\hline Prospect 6 & $\begin{array}{l}50 \% \text { chance of a loss of } £ 0 \text { and } 50 \% \text { chance of a loss } \\
\text { of } £ 1000\end{array}$ & Certainty equivalent, $L_{6}$ \\
\hline \multicolumn{3}{|c|}{ Mixed gains and losses } \\
\hline Prospect 7 & $\begin{array}{l}50 \% \text { chance of a gain of } G_{1} \text { and } 50 \% \text { chance of a loss } \\
\text { of } M_{7}\end{array}$ & Certainty equivalent, $£ 0$ \\
\hline Prospect 8 & $\begin{array}{l}50 \% \text { chance of a gain of } G_{2} \text { and } 50 \% \text { chance of a loss } \\
\text { of } M_{8}\end{array}$ & Certainty equivalent, $£ 0$ \\
\hline Prospect 9 & $\begin{array}{l}50 \% \text { chance of a gain of } G_{3} \text { and } 50 \% \text { chance of a loss } \\
\text { of } M_{9}\end{array}$ & Certainty equivalent, $£ 0$ \\
\hline
\end{tabular}

Throughout the paper, we confine ourselves to the iso-elastic functional form of Eq. (3), which requires estimation of the three parameters $\alpha, \beta$ and $\lambda$. The estimation is performed in three stages:

- First, to estimate $\alpha$, respondents are asked to choose prospects in the gain domain only, comparing a certain outcome with a prospect containing only gains

- Second, to estimate $\beta$, respondents are asked to choose prospects in the loss domain only, comparing a certain outcome with a prospect containing only losses

- Third, respondents are asked to choose prospects with both gains and losses and the results are used to estimate $\lambda$ conditional on the estimates of $\alpha$ and $\beta$ from the first two stages.

A total of nine prospects (three for gains only, three for losses only and three involving both gains and losses) were presented to each individual: these are described in Table 2. A detailed description of our method for eliciting preferences can be found in Abdellaoui et al. (2008, p. 263).

For each prospect, the certainty equivalent was obtained by a series of six steps using an iterative bisection method requiring the participant to choose either the risky prospect or a certain prospect offering a fixed amount. Initially, the fixed amount was set equal to the expected value of the risky prospect. In each succeeding iteration, the certain prospect was reduced (increased) by $50 \%$ of the difference 
between the values of the risky and certain prospects if the respondent's previous choice had been to accept (reject) the certain prospect; the respondent was then asked to choose again. After six iterations, the result of this process is an interval in which the certainty equivalent (or indifference value) should lie and we took the midpoint of this interval as the estimator of the indifference value.

The final three prospects involved both gains and losses and depended on the certainty equivalents elicited from Prospects 1, 2 and 3. Thus, in Prospect 7, participants were initially asked to choose between a riskless amount of $£ 0$ and a risky prospect offering a $50 \%$ chance of a gain of $G_{1}$ (i.e., the certainty equivalent elicited from Prospect 1) and 50\% chance of a loss of the same amount. Then, depending on the choice made, the loss amount in the next iteration was either increased or decreased (using the same bisection method employed in Prospects 1-6). As before, this was repeated for six iterations to elicit the amount $M_{7}$ such that the individual is indifferent between a riskless amount of $£ 0$ and a risky prospect offering a $50 \%$ chance of a gain of $G_{1}$ and a $50 \%$ chance of a loss of $M_{7}$. This process was then repeated for Prospect 8 (using $G_{2}$ and eliciting a corresponding loss amount $M_{8}$ ) and Prospect 9 (using $G_{3}$ and eliciting a corresponding loss amount $M_{9}$ ); see third column of Table 2.

The fact that we asked the questions in the order shown in Table 2 means that there is potentially an anchoring effect. An alternative approach would have been to ask the first six questions in a random order, but Abdellaoui et al. (2008, p. 253) report that their subjects (47 graduate students) were less confused if they answered all the gains questions first, followed by all the loss questions, ending with the mixed questions and we decided that it was safest to use the order shown.

If there were no experimental or sampling error, then the certainty equivalents $G_{1}, G_{2}$ and $G_{3}$ would be related to the prospects in the gain domain as follows:

$$
\begin{aligned}
& v\left(G_{1}\right)=0.5 \times v(10)+0.5 \times v(0) \Rightarrow G_{1}^{\alpha}=0.5 \times 10^{\alpha} \\
& v\left(G_{2}\right)=0.5 \times v(100)+0.5 \times v(0) \Rightarrow G_{2}^{\alpha}=0.5 \times 100^{\alpha} \\
& v\left(G_{3}\right)=0.5 \times v(1000)+0.5 \times v(0) \Rightarrow G_{3}^{\alpha}=0.5 \times 1000^{\alpha}
\end{aligned}
$$

To estimate the parameter $\alpha$ from our noisy data, we start by defining $g_{1}^{\alpha} \equiv G_{1}^{\alpha} / 10^{\alpha}, g_{2}^{\alpha} \equiv G_{2}^{\alpha} / 100^{\alpha}$ etc., suggesting the following econometric model:

$$
g_{i}=0.5^{1 / \alpha}+\varepsilon_{i}
$$

where the error $\varepsilon_{i}$ is due to experimental and sampling error. This can then be used to estimate the parameter $\alpha$ by non-linear least squares (NLS). At this point, we deviate from Abdellaoui et al. (2008) in one important respect. Having asked each individual only nine questions, we do not attempt to estimate parameters for each individual respondent. In Online Appendix A1.2, we show that the NLS parameter estimates tend to be biased upwards in very small samples and, to avoid this bias, we estimate the value of $\alpha$ for groups of respondents and not for individuals separately. The estimation of $\beta$ using prospects 4,5 and 6 follows an analogous procedure.

The last step in the process is the estimation of the direct loss aversion parameter, $\lambda$, which is conditional on the estimates for $\alpha$ and $\beta$. We note that there are two 
issues with the estimates of $\lambda$. The first is econometric: because $\lambda$ is estimated in a two-stage procedure, where both stages are non-linear, we are much less certain about the small-sample properties of the estimates (we calculate the standard errors by bootstrapping). The second is conceptual: the absolute value of $\lambda$ depends upon the units of measurement (it is homogeneous of degree $\beta-\alpha$ in the magnitude of gains and losses). This makes comparison of $\lambda$ parameters across different studies problematic: direct comparison is meaningful only when (i) the experiments in the various studies involve very similar magnitudes of gains and losses, or (ii) the studies involve similar values of $\alpha$ and $\beta$.

We will work with the measure of relative loss aversion defined in Eq. (6). When $\beta \neq \alpha$ an individual can be loss averse for some values of $x$ and loss seeking for other values. In our estimation analysis below, in all cases but one, ${ }^{5}$ we find that $\beta>\alpha$ and $\lambda \approx 1$ : this means that individuals are loss averse (i.e., $\Lambda(x)>1$ ) if $x>1$ and loss seeking (i.e., $\Lambda(x)<1$ ) if $x<1$. Since our unit of measurement is the pound sterling, it seems reasonable to confine ourselves to values of $x>1$. However, because the function $\Lambda(x)$ is homogenous of order $\beta-\alpha$, the magnitude of loss aversion also depends upon the size of $x$. We report below in Table 3 our estimate of $\Lambda(500)$ with the associated $90 \%$ confidence interval estimated by boot-strapping. ${ }^{67}$ By itself, the fact that $\lambda \approx 1$ does not imply an absence of loss aversion: whether individuals are loss averse depends, as Eq. (6) shows, on the values of $x, \alpha$ and $\beta$, as well as $\lambda$.

\section{Survey analysis}

\subsection{Bivariate analysis}

We analyse the full set of 4016 survey responses. Among these are some respondents who give answers which appear inconsistent, for example $G_{2}<G_{1}$. Respondents with at least one such inconsistency comprise $16 \%$ of our data set, raising the question of what to do with these individuals. One possibility is to accept that they are hopelessly confused and hence should be omitted from the analysis. On the other hand, they may merely have made one mistake in a particular direction (in the previous example, choosing a value of $G_{2}$ which is too small) and there may be other individuals who made a mistake in the other direction (i.e., $G_{2}$ too large, but still with $G_{2}>G_{1}$ ): omitting the first group could lead to biased estimates. As a robustness test, we consider in Online Appendix 3 a reduced sample which satisfy $G_{1}<G_{2}<G_{3}$ and $L_{4}<L_{5}<L_{6}$ and it turns out that the question is moot, since the differences in the parameter estimates are small (typically about 0.02 for $\alpha$ and -0.05 for $\beta$ ), indicating that the reduced sample is very marginally both less risk

\footnotetext{
5 The single counter-example is for the sub-sample of respondents who report their annual income to be above $£ 50,000$ per year, where $\alpha=0.7901$ and $\beta=0.7896$, i.e., the parameter estimates are effectively equal.

6 Note that $E[x]=500$ in Prospects 3 and 6 in Table 2.

7 Table A4 in Online Appendix 2 additionally reports estimates of $\Lambda(5)$ and $\Lambda(50)$.
} 


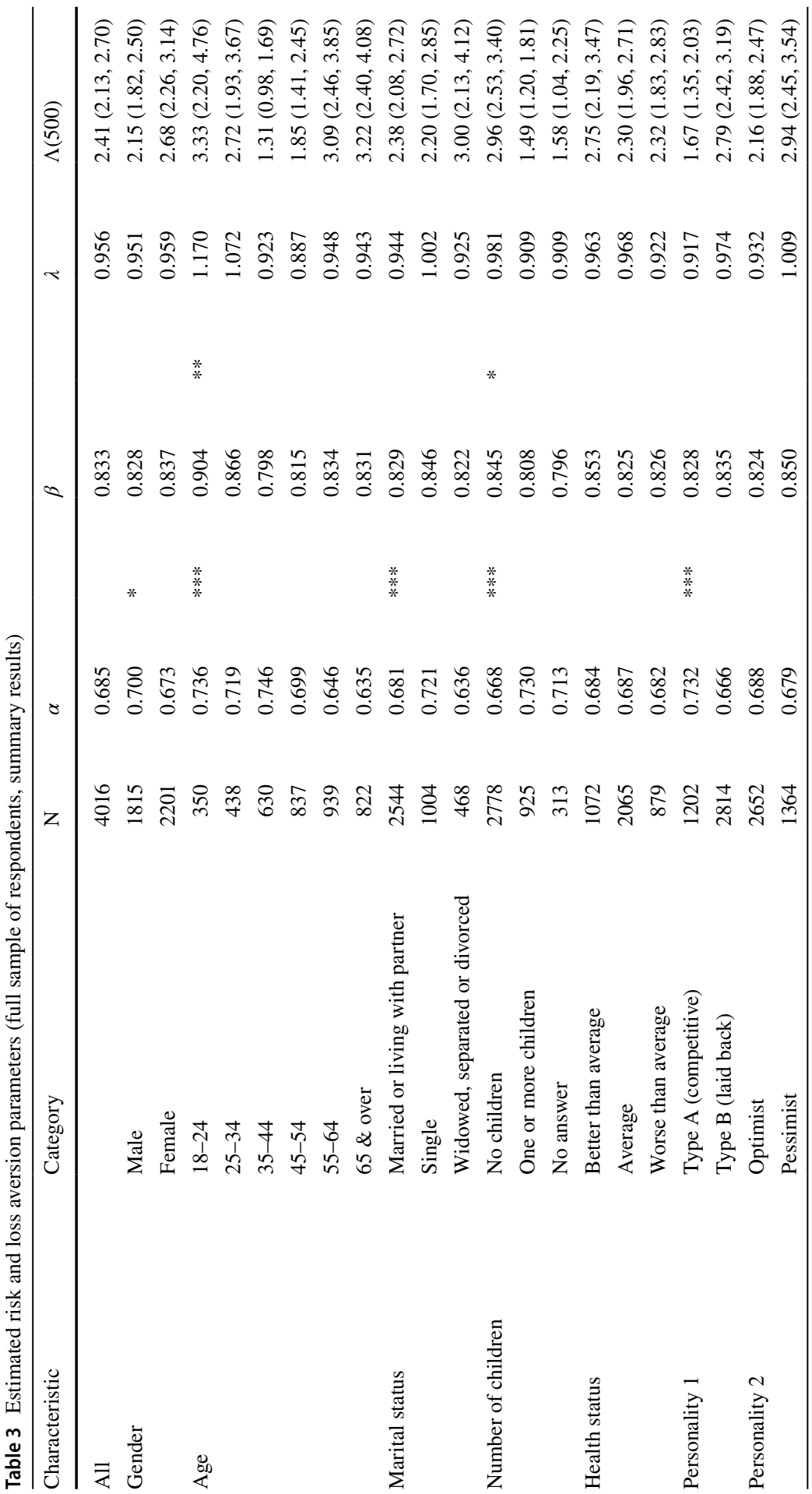




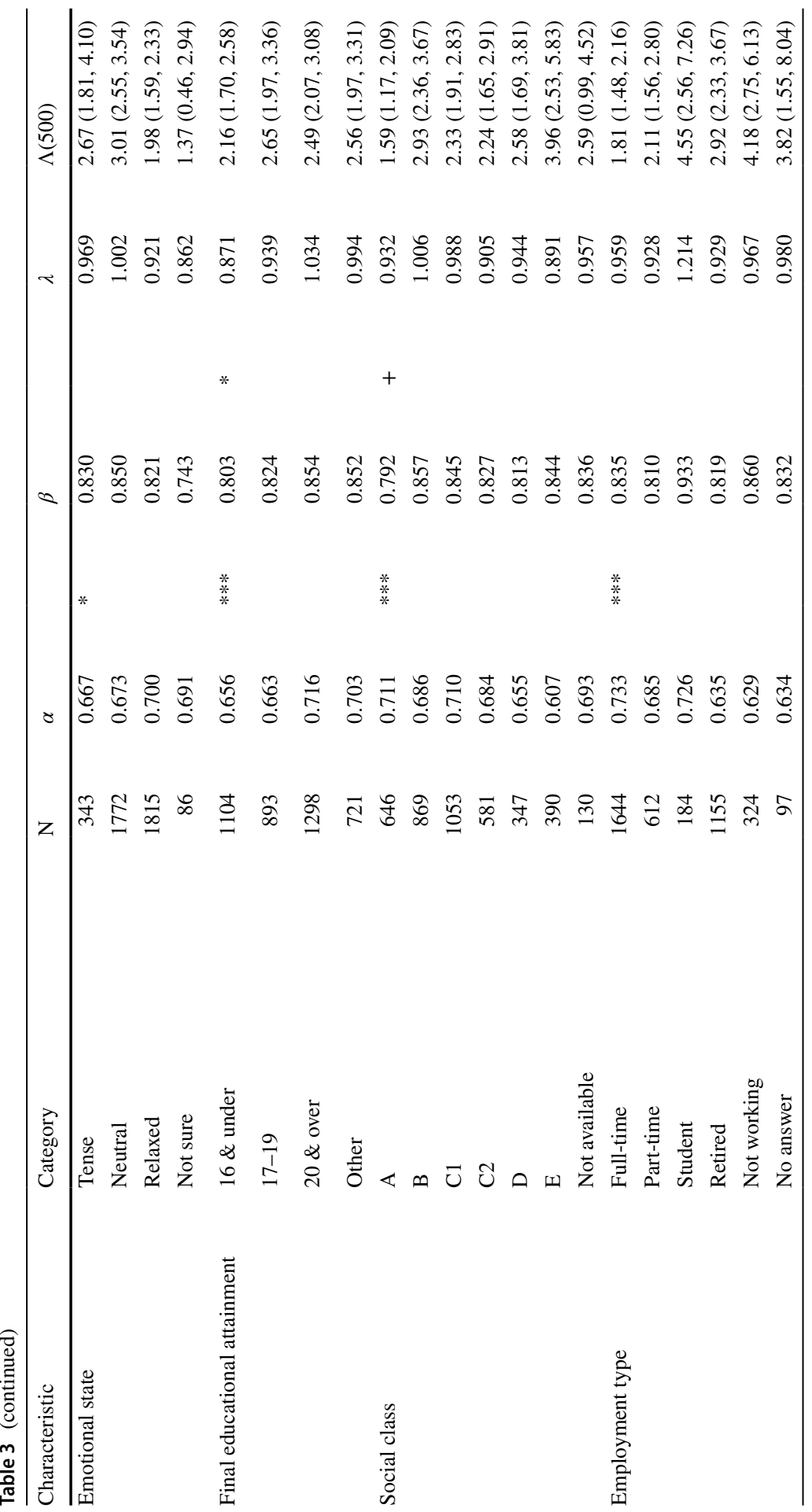




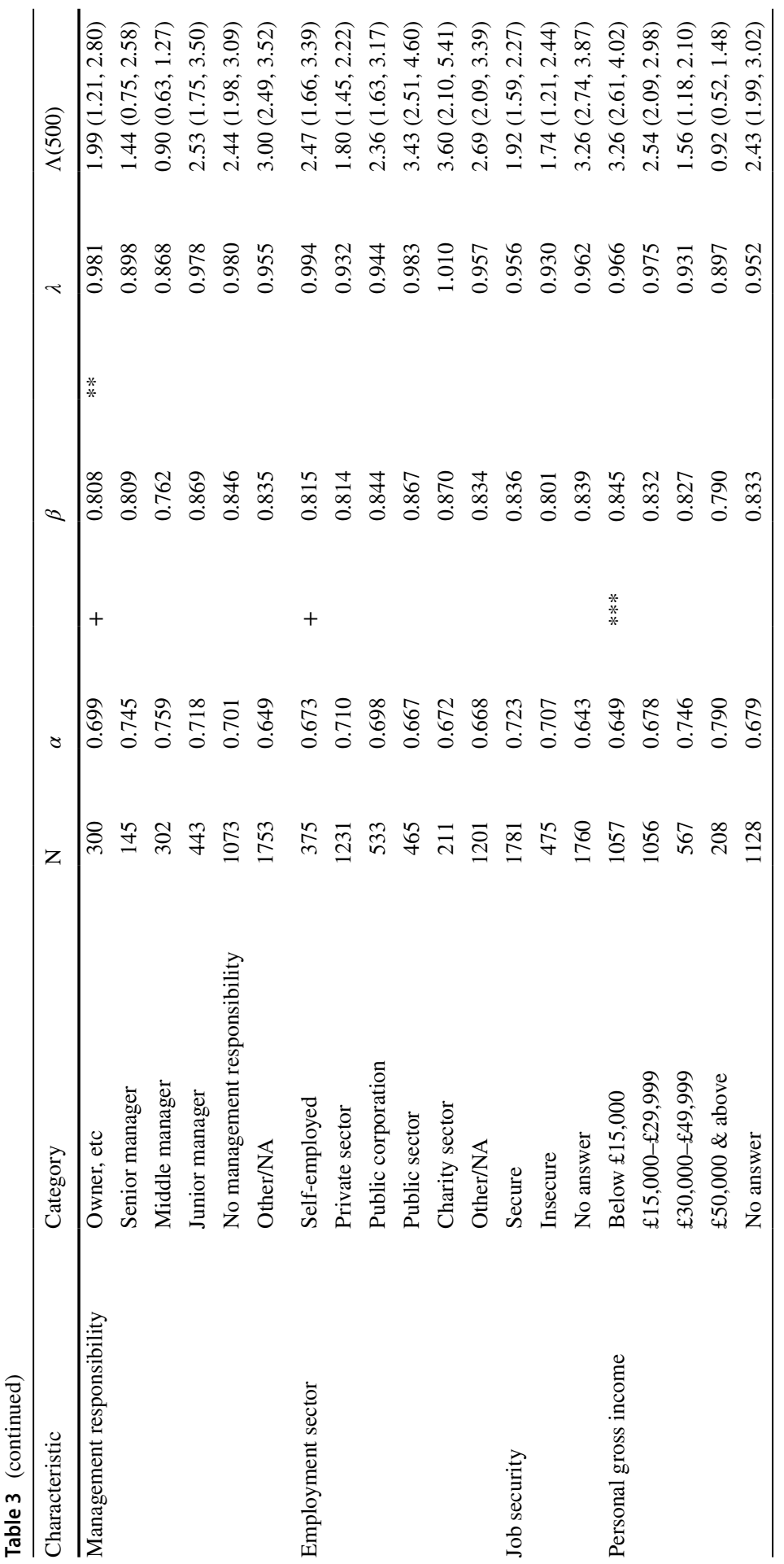




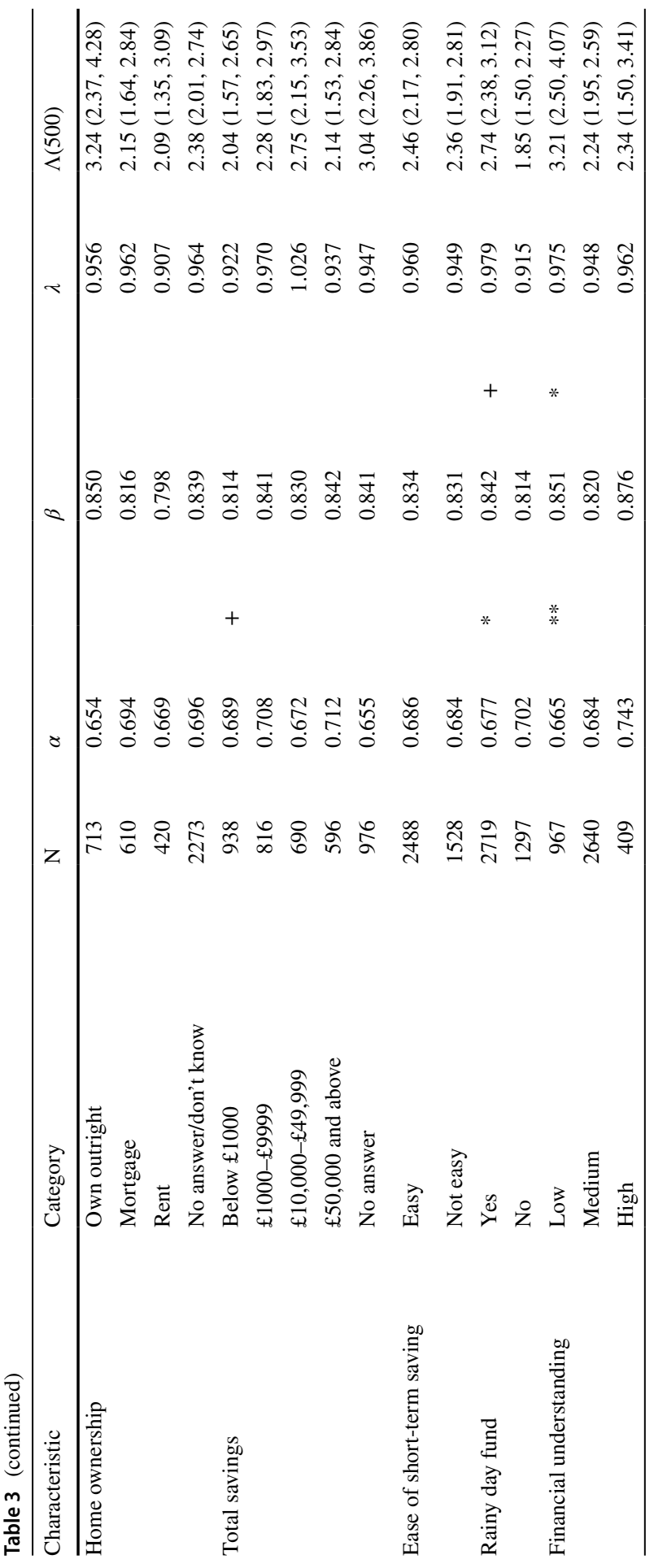




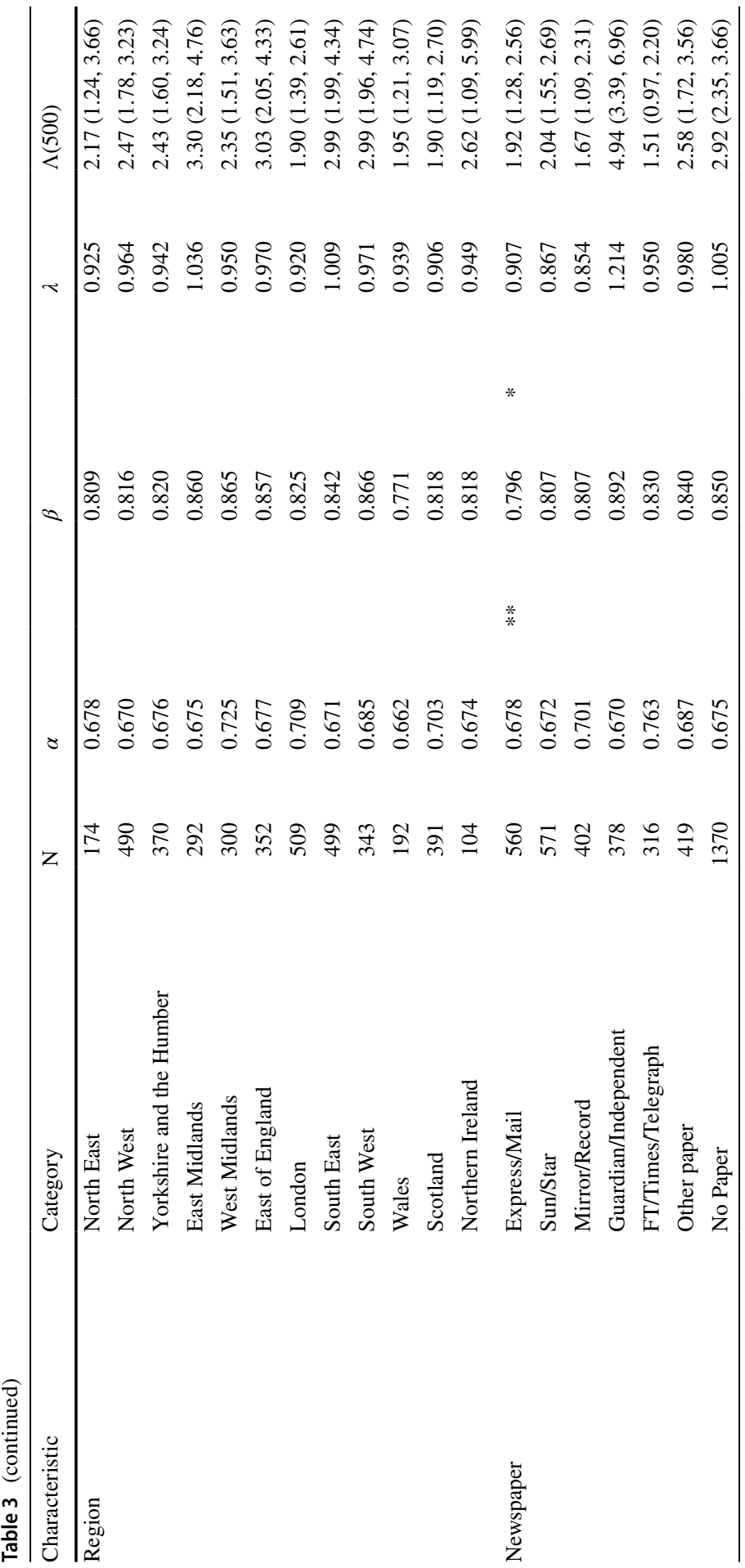




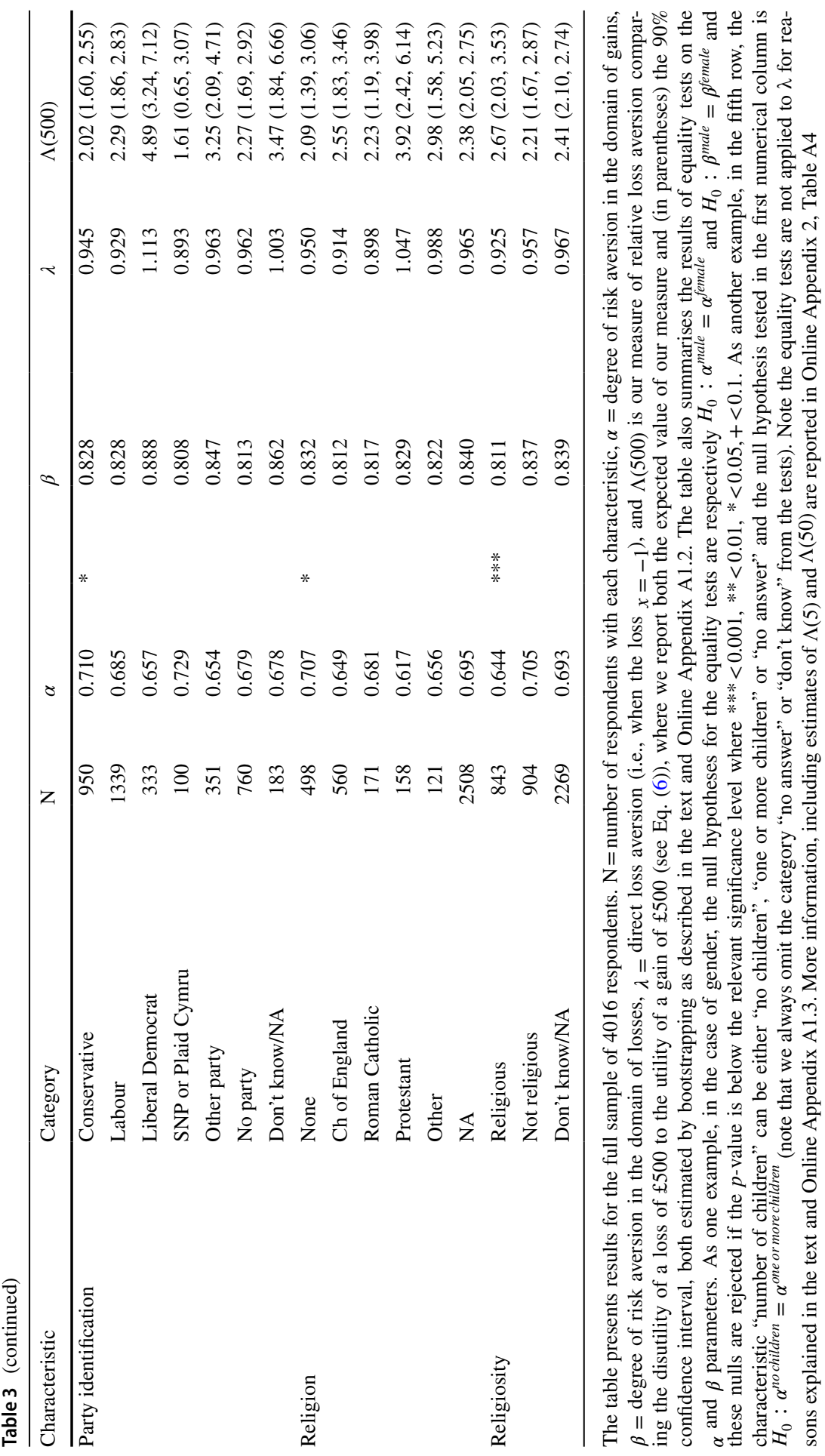


averse in the gain domain and more risk seeking in the loss domain than the full sample).

The first part of our analysis reports estimates of the values of $\alpha, \beta$ and $\lambda$ both for the full sample and for sub-samples of the full sample based on the survey respondents' 25 profiling characteristics. ${ }^{8}$ It is important to note that none of the results in this section necessarily indicate a causal relationship: they are bivariate comparisons between $\alpha, \beta$ and $\lambda$ and a particular profiling characteristic. The measured effect could be influenced by omitted variable bias (failing to control for confounding effects, whereby the values of a risk or loss aversion parameter and a particular profiling characteristic are jointly determined by a third unidentified factor) or by reverse causation (some of the variables such as savings may be determined by $\alpha, \beta$ and $\lambda$ ).

For the whole sample, we have the following estimates:

\begin{tabular}{llllll}
\hline $\begin{array}{l}\alpha \\
\text { (std. err.) }\end{array}$ & $\begin{array}{l}\beta \\
\text { (std. err.) }\end{array}$ & $\begin{array}{l}\lambda \\
(\text { std. err.) }\end{array}$ & $\begin{array}{l}\Lambda(5) \\
(90 \% \text { c.i. })\end{array}$ & $\begin{array}{l}\Lambda(50) \\
(90 \% \text { c.i. })\end{array}$ & $\begin{array}{l}\Lambda(500) \\
(90 \% \text { c.i. })\end{array}$ \\
\hline 0.685 & 0.833 & 0.956 & 1.21 & 1.71 & 2.41 \\
$(0.005)$ & $(0.008)$ & $(0.011)$ & $(1.16,1.27)$ & $(1.57,1.85)$ & $(2.13,2.70)$ \\
\hline
\end{tabular}

Our point estimate across the whole sample for $\alpha$ is 0.685 and for $\beta$ it is 0.833: combined with an estimate of $\lambda$ of 0.956 , these are the estimates used to plot Fig. 1 above. The $\alpha$ and $\beta$ estimates are much lower than those reported by Abdellaoui et al. (2008) who get median individual estimates of 0.86 and 1.06, which are respectively $26 \%$ and $27 \%$ higher than our estimates. As previously mentioned, this may be due to a small-sample upward bias from estimating the parameters at the individual level when there are only a relatively small number of questions per individual. Also as previously discussed, the estimates of $\lambda$ are homogeneous of degree $\beta-\alpha$ and cannot be easily compared. For this reason, we do not view the difference between our estimated $\lambda$ value close to unity with the median value of 2.61 reported by Abdellaoui et al. (2008) as informative. A striking feature is that $\beta>\alpha$, meaning that the marginal disutility of a loss exceeds the marginal utility of a gain-and this applies not only for the whole sample but for each of the 25 characteristics as Table 3 shows. Further, despite the finding that $\lambda \approx 1$ (which again holds across most characteristics), the fact that $\beta>\alpha$ implies individuals are loss averse (i.e., $\Lambda(x)>1$ ) when $x$ is larger than unity, effectively for all non-trivial values. For the sample as a whole, $\Lambda(500)=2.41$, which means that the loss of $£ 500$ causes 2.41 times more unhappiness than a gain of $£ 500$ would cause happiness. $\Lambda(x)$ is always greater than unity and increases with $x$.

\footnotetext{
${ }^{8}$ Note that nearly all of our potential correlates for $\alpha, \beta$ and $\lambda$ are categorical variables, either because they are truly categorical (e.g., gender) or because of the way that the data were collected (e.g., the question about income asked for income in bands). In some cases, we have grouped categories together because the more precise categories have a relatively small number of observations.
} 
The table containing the full set of results across all 25 profiling characteristics is very long and is presented in Table A4 in Online Appendix 2. Table 3 presents a summary of the results.

We start with the issue of gender, where there is a large literature suggesting that women are more risk averse than men (e.g., Bajtelsmit and Bernasek 1996; Barber and Odean 2001; Borghans et al. 2009; Croson and Gneezy, 2009; Dohmen et al. 2011; Finucane et al. 2000; Jianakoplos and Bernasek 1998; Powell and Ansic 1997; Schubert et al. 1999; Sarin and Wieland 2012; Scottish Friendly 2018; L'Haridon and Vieider, 2019). We observe that the male $\alpha$ is above average, while the female $\alpha$ is below average (with both below unity), and * indicates that the difference between men and women is statistically significant at the 5\% level. This shows that women are more risk averse in the domain of gains than men. By contrast, the male and female $\beta$ parameters are not significantly different, suggesting that men and women are equally risk seeking in the domain of losses. However, the statistically significant difference in $\alpha$ translates into a statistically significant difference in $\Lambda(500)$. The $90 \%$ confidence interval is shown to the right of the point estimate.

The second demographic variable in our data set is age. Most early studies show that risk aversion follows a U-shaped pattern with age (e.g., Bakshi and Chen 1994; Pålsson 1996; Riley and Chow 1992). More recent studies show more mixed results: some show older people can be more risk averse than younger adults (e.g., Albert and Duffy 2012; Bonsang and Dohmen 2015), others show that older people can be more risk seeking than younger adults (e.g., Kellen et al. 2017), while others show no clear-cut results (e.g., Mata et al. 2011).

Table 3 shows the parameter estimates for six age groups. The $\alpha$ estimates have a broad hump-shaped pattern, with a peak (implying risk aversion in the domain of gains is lowest) in early middle age (35-44). In higher age ranges, it declines uniformly. It is lower in lower age ranges, although 18-24 years olds are less risk averse than 25-34 years olds. These differences are statistically significant. The $\beta$ estimates exhibit a U-shaped pattern, with the lowest value (indicating that risk seeking in the domain of losses is greatest) in the 35-44 age range. The value is highest, indicating the lowest willingness to take risks in the loss domain, in the 18-24 years age range. Again, these differences are statistically significant. The estimated loss aversion parameter, $\lambda$, also has a U-shaped pattern, reaching a minimum in later middle age (45-54) and it is highest with 18-24 years olds. So our survey respondents appear to be both less risk averse and less loss averse, as well as more risk seeking if facing losses, in middle age than at earlier or later ages. This is consistent with the early studies. As a further check on this, we break down our estimates by both age and gender and this confirms that the U-shaped pattern is found for both men and women: these estimates were used to plot Fig. 2 (detailed results are reported in Online Appendix 2).

The degree of risk aversion can also be influenced by marital status. Hallahan et al. (2003) argue that married couples have greater capacity to absorb undesirable outcomes than singles. Grable and Lytton (1998), Jianakoplos and Bernasek (1998, 2006), Sung and Hanna (1996), and Yao and Hanna (2005) provide evidence that single women are more risk averse than single men or married couples. However, when married couples are analysed separately, single women are more risk averse than married men, but less risk averse than married women. Some studies find that 
single people actually take more risks (e.g., Cohn et al. 1975; Dohmen et al. 2011; Roussanov and Savor 2014). Our data set indicates that widowed, divorced and separated people are the most risk averse in the gain domain, while single people are the least, with partnered people lying between; the differences are statistically significant. Since the existing literature has not previously examined widowed, divorced and separated people, this would appear to be a new finding. We offer the following possible explanations: they could have (i) experienced a sharp and sudden fall in income, (ii) to provide for dependants (both younger and older) and (iii) become more cautious as a result of their negative experience. On the other hand, their risk seeking behaviour in the loss domain is greater than the other two groups (although the difference is not significant), and they appear to be less loss averse.

Having children tends to be associated with higher risk aversion according to Chaulk et al. (2003), Hallahan et al. (2004) and Gilliam et al. (2010). However, our study shows people without children are more risk averse in the gain domain, less risk taking in the loss domain, and more loss averse overall than people with children. On the face of it, this result might seem surprising. One might have thought that having children would make people more loss averse. But the causality could be the other way around: people who are both risk and loss averse might decide not to have children.

We briefly summarise the remaining findings in Table 3. To judge whether there is a relationship between a particular variable and the parameter estimates, we concentrate on the equality tests rather than looking at the significance of individual parameter estimates.

There are several variables which appear to have no systematic correlation with the preference parameters. These are health status, job security, home ownership, how easy respondents find it to save short term, or the region of the UK where the respondent lives.

Turning to variables which do have a systematic correlation, we begin with personality type. When comparing personality type 1 (competitive $\mathrm{v}$ laid-back respondents), there are very large differences in loss aversion, despite the parameter estimates for $\beta$ being almost the same: competitive people are less loss averse than laid-back respondents. When comparing personality type 2 (optimists v pessimists), both $\alpha$ and $\beta$ appear similar (and the difference is statistically insignificant), but again loss aversion is very different: optimists are less loss averse than pessimists. In both of these cases, the parameter which drives the difference in loss aversion is $\lambda$ rather than the curvature parameters: this is despite the fact that $\lambda$ is the parameter which appears to vary less across sub-groups based on other variables. A consequence of this would appear to be that personality type may influence loss aversion via a different route than the socio-economic variables, considered below. Although there are also statistically significant differences in the estimates of $\alpha$, a similar point could be made about the self-reported emotional state.

The parameters $\alpha, \beta$ and $\lambda$ are very different across different educational attainment groups, but the effects partly cancel out and so the differences in relative loss aversion are much smaller and statistically insignificant. The parameters $\alpha$ and $\beta$ vary with self-reported financial understanding and the differences are statistically significant, but again the differences in relative loss aversion are smaller and only 
respondents with low self-reported financial understanding have a significantly higher measure.

There is a strong relationship between preferences and socio-economic variables: social class, employment status, management responsibility, employment sector, income, political party and newspaper. These variables may well be correlated with each other. Many other studies have examined the effect of similar variables (e.g., Grable 2000; Hartog et al. 2002; Campbell 2006; Guiso and Paiella 2008; Paravisini et al. 2017). The evidence seems fairly clear that full-time workers, people with management responsibility, private sector workers, people with higher incomes, reading more right-wing broadsheet newspapers and possibly more conservative politically tend to be less risk averse and less loss averse than other groups. Take income for example. Table 3 shows that relative loss aversion declines as income increases and the point estimate at 0.92 for $\Lambda(500)$ is actually below unity for incomes above $£ 50,000$, implying that the disutility of a loss of $£ 500$ is less than the utility of a gain of $£ 500$ (although the $90 \%$ confidence interval suggests that the estimate is not significantly different from unity).

The issue of direction of causation is most clearly highlighted in self-reported savings. Total reported savings (excluding pension assets) demonstrate little relationship to the preference parameters, but this may be because total savings is highly correlated with other factors, such as age and income. There is, however, a strong positive correlation between higher loss aversion and having a rainy-day fund, suggesting that loss aversion might be a significant determinant of precautionary saving. There is a negative correlation between loss aversion and financial understanding, which is unsurprising since other studies have shown the importance of financial literacy (e.g., Bluethgen et al. 2008; Behrman et al. 2012; Lusardi and Mitchell 2014).

Our final profiling characteristics are religion and religiosity: for both these questions there are relatively few responses. Results for these variables are not driven by non-Christian religions, since the total number of Jews, Moslems, Hindus and Sikhs is only $3 \%$ of the sample. Non-religious people and Roman Catholics have higher values of $\alpha$ (indicating lower risk aversion in the gain domain) than all other religious affiliations and respondents who report themselves to be religious are significantly more risk averse than those who report themselves as being non-religious. However, there are no significant differences in the loss domain.

\subsection{Analysing graduate students}

So far our results are not directly comparable with existing studies, such as Tversky and Kahneman (1992) or Abdellaoui et al. (2008). In order to make a direct comparison, we would need to analyse graduate students. To do this, we examine respondents in full-time education aged 21-23 of whom there are 71 graduates in our sample. This compares with 25 in the Tversky and Kahneman (1992) study and 47 in the Abdellaoui et al. (2008) study.

Both of these studies estimate parameters separately for each individual respondent and then report the median of the individual estimates. Table 4 presents these median estimates alongside our estimates for the pooled sub-sample of our respondents who are graduate students. The table shows the results for a homogeneous 
Table 4 Estimated loss aversion parameters for graduate students in three studies

\begin{tabular}{llllll}
\hline & $\mathrm{N}$ & $\alpha$ & $\beta$ & $\lambda$ & $\Lambda(1000)$ \\
\hline This study & 71 & 0.703 & 0.924 & 1.256 & 7.08 \\
& & $(0.034)^{\mathrm{a}}$ & $(0.050)^{\mathrm{a}}$ & $(0.119)^{\mathrm{a}}$ & $(2.86,14.97)^{\mathrm{b}}$ \\
$\begin{array}{l}\text { Tversky and Kahneman } \\
\quad \text { (1992, p. 311) }\end{array}$ & 25 & 0.88 & 0.88 & 2.25 & 2.25 \\
Abdellaoui et al. (2008) & 47 & $0.86^{\mathrm{c}}$ & $1.06^{\mathrm{c}, \mathrm{d}}$ & - & 2.61 \\
& & $(0.66,1.08)^{\mathrm{e}}$ & $(0.92,1.49)^{\mathrm{e}}$ & & $(1.51,5.51)^{\mathrm{e}}$ \\
\hline
\end{tabular}

The table presents results for the graduate students in our study together with those from two other studies. $\mathrm{N}=$ number of respondents, $\alpha=$ degree of risk aversion in the domain of gains, $\beta=$ degree of risk aversion in the domain of losses, $\lambda=$ direct loss aversion (i.e., when the loss $x=-1$ ), and $\Lambda(1000)$ is relative loss aversion comparing the disutility of a loss of 1000 with the utility of a gain of 1000 (see Eq. (6)).

${ }^{\text {a }}$ Standard errors

${ }^{\mathrm{b}} 90 \%$ confidence interval

${ }^{c}$ Median of estimates of individuals' parameters: all estimates from Abdellaoui et al. (2008) are from Table 6

${ }^{\mathrm{d}}$ This is significantly different from unity

e Inter-quartile range of estimates of individuals' parameters. To enable comparison with the other respondents in our study, we report the following for our 71 graduate students: $\Lambda(5)=1.81(1.31,2.39)$ $\Lambda(50)=3.05(1.70,4.84)$ and $\Lambda(500)=5.24(2.20,9.77)$

group of respondents across three studies, although there is no particular reason to expect that groups of students in different countries and at different times should have identical LA parameters.

We make the following observations. Our $\alpha$ estimate is significantly below that of Tversky and Kahneman (1992)_indicating greater risk aversion in the gain domain-but our $\beta$ estimate is not significantly different. Tversky and Kahneman also find that $\alpha=\beta$ which means that their estimated $\lambda=2.25$ is independent of the gain or loss amount, $x$. However, this does not hold when $\alpha \neq \beta$ which is likely to be the general case. The Abdellaoui et al. (2008) estimates of $\alpha$ and $\beta$ are, respectively, $22 \%$ and $15 \%$ higher than for our students and this, together with their finding that $\beta$ is significantly greater than unity, could reflect the small-sample bias in the estimator they used (see Online Appendix A1.2).

Since Abdellaoui et al. (2008, pp. 253-254) use a normalisation constant of $€ 1000$, we report $\Lambda(1000)$ for the three studies (ignoring the small differences arising from the use of different currencies). The relative loss aversion coefficient for our group of students (7.08) is much higher than for the other groups, largely because our students have such a low $\alpha$ estimate. Nevertheless, the difference $\beta-\alpha$ at around 0.2 is similar for our study and the Abdellaoui et al. (2008) study, indicating that the elasticity of relative loss aversion with respect to the magnitude of gains and losses will be similar. Overall, it seems fair to conclude that the three groups of students have different risk and loss attitudes.

Table 4 also highlights a major contribution of our study: looking at the behaviour of students may be highly misleading when it comes to determining risk and loss aversion for the population as a whole. Our students are very different from the 
wider population in surprising ways. Comparing the first rows of Tables 3 and 4, we can see that our graduate students are less risk averse in the gain domain, less risk seeking in the loss domain, but also much more loss averse overall: $\Lambda(500)=5.24$ compared with 2.41 for the overall sample. Our 71 graduate students also differ from the 113 other students in the sample: the former are more risk averse in the gain domain, more risk seeking in the loss domain, but overall more loss averse. This shows the importance of a study that considers all members of society.

\subsection{Multivariate analysis}

In Sect. 3.1, we presented correlations between the LA parameters and various profiling characteristics. In this section, we report multivariate correlations.

Table 5 reports NLS estimates of two separate multivariate regressions for $\alpha$ and $\beta$ which includes the profiling characteristics as explanatory variables. The estimates can be interpreted as partial correlations between the dependent variable and a potential explanatory variable, conditional on holding all the other potential explanatory variables fixed. Apart from the constant term, what is reported are estimated deviations from a reference individual who is a member of the first group in the list of each profiling characteristic (see Table 3 or the footnote to Table 5). Alongside the parameter estimates, we present the result of hypotheses tests for there being no correlation, i.e., the parameters on the deviations for a given characteristic equalling zero: these tests correspond to the equality tests of the parameters in Table 3. In this section, we concentrate on the differences between the simple correlations and the multivariate correlations.

For example, holding other characteristics constant the difference in $\alpha$ between men and women is reported in the second row as -0.005 and this is statistically insignificant (so there is no $*$ in the adjacent column). We can compare this to the unconditional estimates in Table 3, where the difference in $\alpha$ between men and women is 0.673 $-0.700=-0.027$, statistically significant at the $5 \%$ level (hence the * in Table 3). In fact, the $p$-value for the equality test rises from 0.013 to 0.642 . This is consistent with the argument in Filippin and Crosetto (2016) and Nelson (2017) that different responses from men and women are due to confounding factors rather than inherent gender differences.

The statistically significant effects of marital status, employment status and religion/religiosity in Table 3 cease to be statistically significant when we control for other variables. The relationship between risk aversion in the gain domain and financial knowledge ceases to be statistically significant, but it remains so in the loss domain. Conversely, while the unconditional effect of savings on risk aversion in the gain domain was only marginally significant $(p=0.098)$, in the conditional specification it is statistically significant $(p=0.026){ }^{9}$

However, the most striking result is that statistically significant relationships between many profiling characteristics and preferences are the same in both the univariate and multivariate analysis: number of children, personality type 1 (competitive $\mathrm{v}$ laid back), social class (although this is marginally significant in the multivariate analysis), income, existence of a rainy-day fund, newspaper readership and political party remain statistically significant.

\footnotetext{
${ }^{9}$ Precise information on all of the $p$-values is reported in Online Appendix Table A6.
} 
Table 5 Multivariate regressions of $\alpha$ and $\beta$ on the profiling characteristics (full sample)

\begin{tabular}{|c|c|c|c|c|c|}
\hline Characteristic/category & Category dummy & $\alpha$ & & $\beta$ & \\
\hline & Constant & 0.713 & & 0.820 & \\
\hline Gender & Female & -0.005 & & 0.009 & \\
\hline \multirow[t]{5}{*}{ Age } & $25-34$ & -0.042 & $* *$ & -0.054 & + \\
\hline & $35-44$ & -0.020 & & -0.104 & \\
\hline & $45-54$ & -0.054 & & -0.091 & \\
\hline & $55-64$ & -0.083 & & -0.080 & \\
\hline & $65 \&$ over & -0.074 & & -0.084 & \\
\hline \multirow[t]{2}{*}{ Marital status } & Single & 0.024 & & -0.029 & \\
\hline & Widowed, separated or divorced & -0.001 & & -0.018 & \\
\hline \multirow[t]{2}{*}{ No of children } & One or more children & 0.033 & $*$ & -0.035 & + \\
\hline & No answer re children & 0.023 & & -0.073 & \\
\hline \multirow[t]{2}{*}{ Health status } & Average & 0.009 & & -0.031 & \\
\hline & Worse than average & 0.024 & & -0.025 & \\
\hline Personality 1 & Type B (laid back) & -0.048 & $* * *$ & 0.011 & \\
\hline Personality 2 & Pessimist & -0.011 & & 0.026 & \\
\hline \multirow[t]{3}{*}{ Emotional state during test } & Neutral & 0.001 & $* *$ & 0.035 & \\
\hline & Relaxed & 0.040 & & 0.015 & \\
\hline & Not sure & 0.034 & & -0.076 & \\
\hline \multirow[t]{3}{*}{ Completed education } & $17-19$ & -0.020 & + & 0.015 & + \\
\hline & $20 \&$ over & 0.016 & & 0.050 & \\
\hline & Other/NA & -0.022 & & 0.058 & \\
\hline \multirow[t]{6}{*}{ Social class } & B & -0.023 & + & 0.069 & + \\
\hline & $\mathrm{C} 1$ & 0.012 & & 0.045 & \\
\hline & $\mathrm{C} 2$ & -0.009 & & 0.047 & \\
\hline & $\mathrm{D}$ & -0.027 & & 0.042 & \\
\hline & $\mathrm{E}$ & -0.044 & & 0.078 & \\
\hline & Not available & -0.006 & & 0.041 & \\
\hline Employment type & Part-time* & -0.018 & & -0.040 & + \\
\hline \multirow[t]{5}{*}{ Management responsibility } & Senior manager & 0.019 & & -0.023 & $* *$ \\
\hline & Middle manager & 0.024 & & -0.074 & \\
\hline & Junior manager & -0.007 & & 0.043 & \\
\hline & None & 0.001 & & 0.020 & \\
\hline & Other/NA & 0.010 & & -0.004 & \\
\hline \multirow[t]{5}{*}{ Employment sector } & Private sector & 0.020 & & -0.008 & \\
\hline & Public corporation & 0.013 & & 0.022 & \\
\hline & Public sector & -0.014 & & 0.047 & \\
\hline & Charity sector & -0.012 & & 0.061 & \\
\hline & Other/NA & 0.011 & & 0.004 & \\
\hline \multirow[t]{2}{*}{ Job security } & Insecure & 0.001 & & -0.031 & \\
\hline & No answer & -0.053 & & -0.013 & \\
\hline
\end{tabular}


Table 5 (continued)

\begin{tabular}{|c|c|c|c|c|c|}
\hline Characteristic/category & Category dummy & $\alpha$ & & $\beta$ & \\
\hline \multirow[t]{4}{*}{ Personal gross income } & $£ 15,000-£ 29,999$ & 0.003 & $*$ & -0.023 & \\
\hline & $£ 30,000-£ 49,999$ & 0.047 & & -0.026 & \\
\hline & $£ 50,000$ or more & 0.075 & & -0.044 & \\
\hline & No answer & 0.015 & & -0.016 & \\
\hline \multirow[t]{3}{*}{ Home ownership } & Mortgage & -0.004 & & -0.039 & + \\
\hline & Rent & 0.005 & & -0.072 & \\
\hline & No answer/don't know & 0.029 & & -0.044 & \\
\hline \multirow[t]{4}{*}{ Savings } & $£ 1000-£ 9999$ & 0.024 & $*$ & 0.003 & \\
\hline & $£ 10,000-£ 49,999$ & -0.001 & & -0.006 & \\
\hline & $£ 50,000$ and above & 0.052 & & 0.005 & \\
\hline & No answer & -0.005 & & 0.013 & \\
\hline Ease of saving & Not easy & 0.007 & & 0.028 & \\
\hline Rainy day fund & No & 0.032 & $*$ & -0.039 & + \\
\hline \multirow[t]{2}{*}{ Financial knowledge } & Medium & 0.015 & & -0.029 & $*$ \\
\hline & High & 0.046 & & 0.041 & \\
\hline \multirow[t]{11}{*}{ Region } & North West & -0.013 & & 0.013 & \\
\hline & Yorkshire and the Humber & -0.006 & & 0.005 & \\
\hline & East Midlands & -0.004 & & 0.056 & \\
\hline & West Midlands & 0.033 & & 0.054 & \\
\hline & East of England & -0.011 & & 0.048 & \\
\hline & London & 0.011 & & 0.015 & \\
\hline & South East & -0.014 & & 0.030 & \\
\hline & South West & 0.002 & & 0.053 & \\
\hline & Wales & -0.015 & & -0.044 & \\
\hline & Scotland & 0.009 & & -0.005 & \\
\hline & Northern Ireland & -0.008 & & 0.011 & \\
\hline \multirow[t]{6}{*}{ Newspaper } & Sun/Star & -0.017 & $* *$ & 0.022 & \\
\hline & Mirror/Record & 0.026 & & 0.028 & \\
\hline & Guardian/Independent & -0.041 & & 0.073 & \\
\hline & FT/Times/Telegraph & 0.049 & & 0.017 & \\
\hline & Other paper & 0.003 & & 0.043 & \\
\hline & No Paper & -0.017 & & 0.055 & \\
\hline \multirow[t]{6}{*}{ Political party } & Labour & -0.017 & + & -0.008 & \\
\hline & Liberal Democrat & -0.054 & & 0.039 & \\
\hline & SNP or Plaid Cymru & 0.039 & & -0.022 & \\
\hline & Other party & -0.030 & & 0.001 & \\
\hline & No party & -0.013 & & -0.040 & \\
\hline & Don't know/NA & -0.018 & & 0.009 & \\
\hline
\end{tabular}


Table 5 (continued)

\begin{tabular}{llcc}
\hline Characteristic/category & Category dummy & $\alpha$ & $\beta$ \\
\hline Religion & Ch of England & -0.010 & 0.010 \\
& Roman Catholic & 0.002 & 0.027 \\
& Protestant & -0.042 & 0.035 \\
& Other & -0.037 & 0.022 \\
& NA & 0.009 & -0.001 \\
Religiosity & Not religious & 0.033 & 0.040 \\
& Don't know/NA & -0.010 & 0.047 \\
\hline
\end{tabular}

The table presents the results of two separate regressions for $\alpha$ (the degree of risk aversion in the domain of gains) and $\beta$ (the degree of risk aversion in the domain of losses) on category dummies for each characteristic that differentiate respondents from a reference individual. The constant term shows the estimated $\alpha$ and $\beta$ for the reference individual and the other coefficients show positive or negative deviations from this. For each category we test for equality across categories, which in this specification is the null hypothesis that all of the deviations are zero: the test $p$-value is summarised by $* * *<0.001, * *<0.01$, $*<0.05,+<0.1$. The reference individual is male, aged $18-24$, married/living with partner, no children, better than average health, Type A (competitive) personality, optimist, tense at the time of the survey, terminal education age of 16 \& under, low financial knowledge, social class A, full-time employment, management responsibility of an owner, self-employed, secure job security, income below $£ 15,000$, owns home outright, savings below $£ 1000$, finds short-term savings easy, has a rainy day fund, Express/Mail reader, Conservative voter, no religion, but religious. Only one employment-status categorical variable is included since the other possibilities (student, retired) are collinear with other categorical variables

Finally in this section, we draw comparison with two other studies that conducted a multivariate analysis. The first is Dohmen et al. (2011, Table A1) which finds that women self-report that they are less likely to take financial risks, after conditioning on other variables.

The second is von Gaudecker et al. (2011) which is the only other study of which we are aware that surveys from a national population. Their sample size, at 1422 individuals, is smaller than ours and they assess far fewer characteristics: only gender, age, education, income, wealth, and whether the respondent has financial knowledge or is the household's financial administrator. While their baseline estimates of the risk and loss aversion parameters $(\gamma=0.0316$ and $\lambda=2.960)$ are not directly comparable with ours, their findings in terms of characteristics can be compared: women are more risk and loss averse than men (even after conditioning on other characteristics such as income), risk aversion increases and loss aversion falls with age, risk aversion decreases and loss aversion increases with education, risk aversion increases and loss aversion falls with income, risk and loss aversion both fall with wealth, and risk and loss aversion are lower for those with financial knowledge or who are the household's financial administrator. These are mostly similar to our findings, although there are some differences. For example, we find: a U-shaped relationship between loss aversion and age, that risk aversion decreases with income, and a hump-shaped relationship between loss aversion and total savings. 


\section{Conclusions}

We have estimated a simple parametric version of the Tversky and Kahneman (1992) value function for a representative sample of around four thousand respondents from the UK. The estimated value function is S-shaped, exhibiting both direct loss aversion (measured by $\Lambda(x)>1$ ), risk aversion in the domain of gains (measured by $\alpha<1$ ), risk seeking behaviour in the domain of losses (measured by $\beta<1$ ), and with the marginal disutility of losses exceeding the marginal utility of gains $(\beta>\alpha)$. In other words, the curvature of the value function is greater in the loss domain than in the gain domain-see Fig. 1.

These findings are consistent with most previous studies, but while these other studies are mainly of students, ours is one of the few studies to sample from a national population. We also have much more detailed information about the respondents to our survey than all previous studies. We had information on 25 profiling characteristics for each respondent which enabled us to conduct both bivariate and multivariate analyses to assess if there is a statistically significant relationship (both unconditionally and conditionally) between the estimated parameters of the respondents' value function and their profiling characteristics. When conditioning on all the characteristics, we find that some characteristics are correlated with loss and risk attitudes in the gain domain only (personality type 1 (competitive $\mathrm{v}$ laid back), emotional state, income, savings, rainy day fund, newspaper and political party), some are correlated in the loss domain only (financial knowledge, employment status, management responsibility, and home ownership), while some are correlated in both domains (age, number of children, education, and social class).

We also document that some characteristics that were found to be unconditionally significant in the bivariate analysis were not significant when conditioned on other characteristics. One example is marital status. We find that widowed, divorced and separated people are more risk averse than partnered people who are, in turn, more risk averse than single people. But these differences disappear when we condition. Another example is gender. Our study shows that women are slightly more loss and risk averse than men, but this is no longer the case when we condition, suggesting that gender differences can possibly be explained by other factors, such as income differences. This result is different from the most similar study to ours, namely von Gaudecker et al. (2011)'s survey of over a thousand Dutch respondents, which finds gender differences in loss and risk attitudes remain, even after conditioning.

Because many existing studies are based on the responses of students, it is interesting to compare our results for the whole sample with a sub-sample of the respondents in our sample who are students. We estimate relative loss aversion for these students to be 5.24 for a loss of $£ 500$ compared with a gain of the same amount. This is more than twice the size of that for the whole sample which is 2.41. This follows because although the value functions for the two groups have similar concavities in the gain domain, the students' value function is much less convex in the loss domain. This clearly emphasises the problem in generalising from studies of students to the population as a whole. 
The existing literature has emphasised the relationship between risk and loss attitudes and factors such as gender, age, education, income, and savings. Our study of a representative sample of the UK population finds that some of these factors (age, education, income, and savings) are also important, but others, in particular gender differences, are not significant, once we have controlled for the other factors. We have also found some other characteristics not previously studied in the literature that influence risk attitudes, in particular, personality type, social class, management responsibility, rainy day fund, newspaper, and political party. By including questions on these factors in a client fact find, financial advisers might be able to get a better fix on the true loss and risk attitudes of their clients. In particular, they can be used to confirm the findings from a more direct elicitation of such attitudes.

Supplementary Information The online version contains supplementary material available at https://doi. org/10.1007/s11166-021-09356-7.

Acknowledgements We are grateful for a Pump Priming Grant from City University of London and to the Pensions Institute for funding the YouGov survey. We would like to thank Leo Brownstein, Michael Henderson, Helen Khamooshi, Alex McIntosh, Simon Mottram, Jake Palenicek, and Michael Wagstaff of YouGov for their support in preparing and conducting the questionnaire used in this study. We should also like to thank Chris Muris for advice on some of the econometric issues raised in the paper and Luca Zarri and Maria Vittoria Levati for general comments. Any remaining errors are the responsibility of the authors.

\section{Declarations}

Conflict of interest The authors declare that they have no conflict of interest.

Open Access This article is licensed under a Creative Commons Attribution 4.0 International License, which permits use, sharing, adaptation, distribution and reproduction in any medium or format, as long as you give appropriate credit to the original author(s) and the source, provide a link to the Creative Commons licence, and indicate if changes were made. The images or other third party material in this article are included in the article's Creative Commons licence, unless indicated otherwise in a credit line to the material. If material is not included in the article's Creative Commons licence and your intended use is not permitted by statutory regulation or exceeds the permitted use, you will need to obtain permission directly from the copyright holder. To view a copy of this licence, visit http://creativecommons.org/licenses/by/4.0/.

\section{References}

Abdellaoui, M., Bleichrodt, H., \& L'Haridon, O. (2008). A tractable method to measure utility and loss aversion under prospect theory. Journal of Risk and Uncertainty, 36(3), 245-266.

Abdellaoui, M., Bleichrodt, H., L'Haridon, O., \& van Dolder, D. (2016). Measuring loss aversion under ambiguity: A method to make prospect theory completely observable. Journal of Risk and Uncertainty, 52(1), 1-20.

Abdellaoui, M., Bleichrodt, H., \& Paraschiv, C. (2007). Loss aversion under prospect theory: A parameter-free measurement. Management Science, 53(10), 1659-1674.

Albert, S. M., \& Duffy, J. (2012). Differences in risk aversion between young and older adults. Neuroscience and Neuroeconomics, 2012(1), 3-9.

Allais, M. (1953). Le comportement de l'homme rationnel devant le risque: Critique des postulats et axiomes de l'école américaine. Econometrica, 21(4), 503-546.

Andersen, S., Harrison, G. W., Lau, M. I., \& Rutström, E. E. (2006). Elicitation using multiple price list formats. Experimental Economics, 9, 383-405. 
Bajtelsmit, V., \& Bernasek, A. (1996). Why do women invest differently than men? Financial Counseling and Planning, 7, 1-10.

Bakshi, G., \& Chen, Z. (1994). Baby boom, population aging and capital markets. Journal of Business, 67, 165-202.

Barber, B. M., \& Odean, T. (2001). Boys will be boys: Gender, overconfidence, and common stock investment. Quarterly Journal of Economics, 116(1), 261-292.

Beattie, J., \& Loomes, G. (1997). The impact of incentives upon risky choice experiments. Journal of Risk and Uncertainty, 14(2), 155-168.

Behrman, J. R., Mitchell, O. S., Soo, C. K., \& Bravo, D. (2012). How financial literacy affects household wealth accumulation. American Economic Review: Papers and Proceedings, 102(3), 300-304.

Bleichrodt, H., Pinto, J. L., \& Wakker, P. P. (2001). Making descriptive use of prospect theory to improve the prescriptive use of expected utility. Management Science, 47(11), 1498-1514.

Bluethgen, R., Gintschel, A., Hackethal, A., \& Müller, A. (2008). Financial advice and individual investors' portfolios. Working Paper, European Business School, Oestrich-Winkel.

Bonsang, E., \& Dohmen, T. (2015). Cognitive ageing and risk attitude. Journal of Economic Behavior and Organization, 112, 112-126.

Borghans, L., Golsteyn, B. H. H., Heckman, J. J., \& Meijers, H. (2009). Gender differences in risk aversion and ambiguity aversion. Journal of the European Economic Association, 7(2-3), 649-658.

Bostic, R., Herrnstein, R. J., \& Luce, R. D. (1990). The effect on the preference reversal of using choice indifferences. Journal of Economic Behavior and Organization, 13, 193-212.

Campbell, J. Y. (2006). Household finance. Journal of Finance, 61(4), 1553-1604.

Camerer, C. F., \& Hogarth, R. M. (1999). The effects of financial incentives in experiments: A review and capital-labor-production framework. Journal of Risk and Uncertainty, 19(1-3), 7-42.

Chaulk, B., Johnson, P. J., \& Bulcroft, R. (2003). Effects of marriage and children on financial risk tolerance: A synthesis of family development and prospect theory. Journal of Family and Economic Issues, 24(3), 257-279.

Cohn, R. A., Lewellen, W. G., Lease, R. C., \& Schlarbaum, G. G. (1975). Individual investor risk aversion and investment portfolio composition. Journal of Finance, 30(2), 605-620.

Croson, R., \& Gneezy, U. (2009). Gender differences in preferences. Journal of Economic Literature, 47(2), 448-474.

Dohmen, T., Falk, A., Huffman, D., Sunde, U., Schupp, J., \& Wagner, G. G. (2011). Individual risk attitudes: Measurement, determinants, and behavioral consequences. Journal of the European Economic Association, 9(3), 522-550.

Etchart-Vincent, N., \& L'Haridon, O. (2011). Monetary incentives in the loss domain: An experimental comparison of three rewarding schemes including real losses. Journal of Risk and Uncertainty, 42(1), 61-83.

Filippin, A., \& Crosetto, P. (2016). A reconsideration of gender differences in risk attitudes. Management Science, 62(11), 3138-3160.

Finucane, M. L., Slovic, P., Mertz, C. K., Flynn, J., \& Satterfield, T. A. (2000). Gender, race, and perceived risk: The 'white male' effect. Health, Risk and Society, 2, 159-172.

Frederick, S., Loewenstein, G., \& O’Donoghue, T. (2002). Time discounting and time preference: A critical review. Journal of Economic Literature, 2, 351-401.

Gilliam, J. E., Chatterjee, S., \& Zhu, D. (2010). Determinants of risk tolerance in the baby boomer cohort. Journal of Business and Economic Research, 8(5), 79-87.

Grable, J. E. (2000). Financial risk tolerance and additional factors that affect risk taking in everyday money matters. Journal of Business and Psychology, 14(4), 625-630.

Grable, J. E., \& Lytton, R. H. (1998). Investor risk tolerance: Testing the efficacy of demographics as differentiating and classifying factors. Journal of Financial Counseling and Planning, 9(1), 61-74.

Guiso, L., \& Paiella, M. (2008). Risk aversion, wealth, and background risk. Journal of the European Economic Association, 6(6), 1109-1150.

Hallahan, T. A., Faff, R. W., \& McKenzie, M. D. (2003). An exploratory investigation of the relation between risk tolerance scores and demographic characteristics. Journal of Multinational Financial Management, 13(4), 483-502.

Hallahan, T. A., Faff, R. W., \& McKenzie, M. D. (2004). An empirical investigation of personal financial risk tolerance. Financial Services Review, 13(1), 57-78.

Hartog, J., Ferrer-i-Carbonell, A., \& Jonker, N. (2002). Linking measured risk aversion to individual characteristics. Kyklos, 55(1), 3-26. 
Holt, C. A., \& Laury, S. K. (2002). Risk aversion and incentive effects. American Economic Review, 92, 1644-1655.

Jianakoplos, N., \& Bernasek, A. (1998). Are women more risk averse? Economic Inquiry, 36, 620-630.

Jianakoplos, N., \& Bernasek, A. (2006). Financial risk taking by age and birth cohort. Southern Economic Journal, 72(4), 981-1001.

Kahneman, D., \& Tversky, A. (1979). Prospect theory: An analysis of decision under risk. Econometrica, 47, 263-292.

Kellen, D., Mata, R., \& Davis-Stober, C. P. (2017). Individual classification of strong risk attitudes: An application across lottery types and age groups. Psychonomic Bulletin and Review, 24(4), 1341-1349.

Köbberling, V., \& Wakker, P. P. (2005). An index of loss aversion. Journal of Economic Theory, 122, $119-131$.

Kreps, D. M., \& Porteus, E. L. (1978). Temporal resolution of uncertainty and dynamic choice theory. Econometrica, 46(1), 185-200.

L'Haridon, O., \& Vieider, F. M. (2019). All over the map: A worldwide comparison of risk preferences. Quantitative Economics, 10, 185-215.

Harrison, G. W., \& Swarthout, J. T. (2016). Cumulative prospect theory in the laboratory: A reconsideration. Georgia State University.

Lusardi, A., \& Mitchell, O. S. (2014). The economic importance of financial literacy: Theory and evidence. Journal of Economic Literature, 52(1), 5-44.

Mata, R., Josef, A. K., Samanez-Larkin, G. R., \& Hertwig, R. (2011). Age differences in risky choice: A meta-analysis. Annals of the New York Academy of Sciences, 1235, 18-29.

Nelson, J. (2017). Gender and risk-taking: Economics, evidence and why the answer matters. Routledge.

Pålsson, A. M. (1996). Does the degree of relative risk aversion vary with household characteristics? Journal of Economic Psychology, 17(6), 771-787.

Paravisini, D., Rappoport, V., \& Ravina, E. (2017). Risk aversion and wealth: Evidence from person-toperson lending portfolios. Management Science, 63(2), 279-297.

Powell, M., \& Ansic, D. (1997). Gender differences in risk behaviour in financial decision-making: An experimental analysis. Journal of Economic Psychology, 18(6), 605-628.

Rabin, M., \& Thaler, R. H. (2001). Anomalies: Risk aversion. Journal of Economic Perspectives, 15, 219-232.

Riley, W. B., \& Chow, K. V. (1992). Asset allocation and individual risk aversion. Financial Analysts Journal, 48, 32-37.

Roussanov, N., \& Savor, P. (2014). Marriage and managers' attitudes to risk. Management Science, 60(10), 2496-2508.

Samuelson, P. A. (1963). Risk and uncertainty: A fallacy of large numbers. Scientia, 98, 108-113.

Sarin, R. K., \& Wieland, A. M. (2012). Gender differences in risk aversion: A theory of when and why. Working Paper, University of California, Los Angeles.

Scholten, M., \& Read, D. (2014). Prospect theory and the 'forgotten' fourfold pattern of risk preferences. Journal of Risk \& Uncertainty, 48(1), 67-83.

Schubert, R., Brown, M., Gysler, M., \& Brachinger, H. W. (1999). Financial decision-making: Are women really more risk-averse? American Economic Review, 89(2), 381-385.

Scottish Friendly. (2018). Breadwinners and losers: Is women's lack of confidence to invest putting their financial future at risk? March, https://www.scottishfriendly.co.uk/news/2018-news-press-releases/ breadwinners-and-losers-womens-lack-confidence-invest-putting-their-financial-future-risk

Sung, J., \& Hanna, S. (1996). Factors related to risk tolerance. Financial Counseling and Planning, 7, 11-20.

Tversky, A., \& Kahneman, D. (1992). Advances in prospect theory: Cumulative representation of uncertainty. Journal of Risk and Uncertainty, 5, 297-323.

von Gaudecker, H. M., van Soest, A., \& Wengström, E. (2011). Heterogeneity in risky choice behavior in a broad population. American Economic Review, 101, 664-694.

Yao, R., \& Hanna, S. D. (2005). The effect of gender and marital status on financial risk tolerance. Journal of Personal Finance, 4(1), 66.

Zank, H. (2010). On probabilities and loss aversion. Theory and Decision, 68(3), 243-261.

Publisher's Note Springer Nature remains neutral with regard to jurisdictional claims in published maps and institutional affiliations. 


\section{Authors and Affiliations}

\section{David Blake $^{1}$ D $\cdot$ Edmund Cannon $^{2}$ D $\cdot$ Douglas Wright $^{1}$ (D)}

$\triangle$ Edmund Cannon

edmund.cannon@bristol.ac.uk

David Blake

d.blake@city.ac.uk

Douglas Wright

dwright@city.ac.uk

1 Bayes Business School, City University of London, 106 Bunhill Row, London EC1Y 8TZ, UK

2 School of Economics, University of Bristol, Priory Road Complex, Priory Road, Bristol BS8 1TU, UK 